\title{
Ceratoplastia lamelar anterior profunda pela técnica da "big-bubble"
}

\author{
Deep anterior lamellar keratoplasty by big-bubble technique \\ Patrick Frensel de Moraes Tzelikis ${ }^{1}$, Juliana Dias dos Santos $^{1}$, Rodrigo Castro Garcez $^{1}$, Leonardo Akaishi ${ }^{1}$
}

\section{RESUMO}

Objetivo: Avaliar a eficácia, segurança e as complicações da técnica de ceratoplastia lamelar anterior profunda (CLAP) realizada através da técnica da "big-bubble". Métodos: Foram avaliados prospectivamente pacientes submetidos à CLAP pela técnica da "big-bubble". Após o procedimento cirúrgico, foi avaliada a acuidade visual sem correção (AVSC), acuidade visual com correção (AVCC), equivalente esférico (EE), topografia corneana, contagem endotelial (CE) e as complicações intra e pós-operatórias Resultados: Foram avaliados 59 olhos de 55 pacientes. A média de seguimento fo de 16 $\pm 7,4$ meses. A AVSC e AVCC média (logMAR) pré-operatória eram de 1,60 \pm 0,33 e $1,00 \pm 0,43$, respectivamente. Após 12 meses da cirurgia, a AVSC e AVCC média melhoraram para 0,86 $\pm 0,39$ e 0,17 $\pm 0,14$, respectivamente. $\mathrm{O} E \mathrm{E}$ médio melhorou de $-8,21 \pm 3,91$ para $-1,82 \pm 3,62$ e o astigmatismo topográfico também apresentou melhora de $-7,9 \pm 3,7$ para $-2,21 \pm 1,7$ ao final de 12 meses de seguimento A média pré-operatória da CE era de 2.377,98 $\pm 263,56$ céls $/ \mathrm{mm}^{2}$, após 12 meses da cirurgia a média da CE reduziu para 1.851,32 $\pm 397,61$ céls $/ \mathrm{mm}^{2}$. A presença de microperfurações ocorreu em 6 casos (10,2\%). Em apenas um paciente foi observado à ocorrência de rejeição estromal e em um caso a presença de midríase paralítica (Urrets-Zavalia) após a cirurgia lamelar.

Conclusão: Apesar de tecnicamente mais complexa a cirurgia de CLAP apresentase como uma excelente opção de tratamento para pacientes com alterações corneanas que apresentam seu endotélio normal.

ClinicalTrials.gov Identifier: NCT00887900

Descritores: Transplante de córnea/métodos; Procedimentos cirúrgicos oftalmológicos/métodos; Lâmina limitante posterior da córnea/cirurgia

\begin{abstract}
Purpose: To evaluate the efficacy, safety, and complications related to the deep anterior lamellar keratoplasty (DALK) using the big-bubble technique.

Methods: A prospective study of patients submitted to DALK using the big-bubble technique was conducted. After the procedure, uncorrected visual acuity (UCVA), best corrected visual acuity (BCVA), spherical equivalent (SE), corneal topography, endothelial cell density, and intraoperative and postoperative complications were evaluated.

Results: Fifty-nine eyes of 55 patients were included in this study. Mean follow-up period was $16 \pm 7.4$ months. Baseline mean UCVA (logMAR) and BCVA was $1.60 \pm 0.33$ and 1.00 \pm 0.43 , respectively. After 12 months, the mean UCVA and BCVA improved to $0.86 \pm 0.39$ and $0.17 \pm 0.14$, respectively. Mean SE improved from $-8.21 \pm 3.91$ to $-1.82 \pm 3.62$ at 12 months. Mean topographic astigmatism improved from $-7.9 \pm 3.7$ to $-2.21 \pm 1.7$ at 12 months. Mean preoperative endothelial cell density was 2,377.98 $\pm 263.56 \mathrm{cell} / \mathrm{s} / \mathrm{mm}^{2}$, after 12 months of surgery the mean endothelial cell density reduced to 1,851.32 \pm $397.61 \mathrm{cells} / \mathrm{mm}^{2}$. Intraoperative microperfuration occurred in 6 cases (10.2\%). One patient developed stromal rejection, and one patient developed fixed dilated pupil (Urrets-Zavalia Syndrome) after the procedure.

Conclusion: Nevertheless, deep anterior lamellar keratoplasty is more technically challenging, yet rewarding choice of surgery for keratoplasty patients who have a healthy endothelial cell count.

ClinicalTrials.gov Identifier: NCT00887900
\end{abstract}

Keywords: Corneal transplantation/methods; Ophthalmologic surgical procedures/ methods; Descemet's membrane/surgery

\section{INTRODUÇÃO}

Tanto as técnicas de transplante lamelar (TL) como as de transplante penetrante (TP) vêm sendo recomendadas para o tratamento de diversas doenças corneanas nos últimos anos. A ceratoplastia penetrante (CP) possui um histórico bastante longo e favorável, sendo uma técnica já bem estabelecida e acompanhada de altas taxas de sucesso quando comparada aos outros diferentes transplantes de órgãos. No entanto, algumas complicações como as rejeições imunológicas relacionadas à CP não podem ser esquecidas. O tipo mais comum de rejeição é a rejeição endotelial, que é observada, nos casos de baixo risco, em aproximadamente $20 \%$ dos pacientes submetidos a este tipo de transplante ${ }^{(1,2)}$. Portanto, a maior desvantagem da CP é a substituição do endotélio do receptor pelo endotélio alogênico do doador, mesmo em pacientes que apresentam seu endotélio normal.

Mais recentemente, diferentes técnicas de ceratoplastia lamelar anterior profunda (CLAP) apresentaram um grande avanço sendo hoje possível realizar um transplante de córnea lamelar em um leito receptor contendo pouco ou nenhum tecido estromal sobre a membrana de Descemet (MD). Essa técnica de transplante de córnea apresenta algumas vantagens quando comparada a CP. Por evitar a substituição do endotélio do paciente, previne-se a ocorrência de uma rejeição endotelial e consequentemente, devido a não necessidade de terapia imunossupressora por um período longo, é possível diminuir a incidência de infecção, glaucoma e catarata ${ }^{(3,4)}$. Além dessas vantagens apresenta uma aderência da ferida cirúrgica superior, as suturas podem ser removidas mais precocemente, e a escolha do tecido doador pode ser menos rigorosa. Apesar destas vantagens, os fatores limitantes para aplicação das técnicas de CL são: nível de dificuldade alta, maior tempo intraoperatório, e a possibilidade de ocorrência de irregularidade na interface entre doador e receptor levando à perda de linhas de visão e pior acuidade visual corrigida no pós-operatório. Nos últimos anos, o que se observa com o aprimoramento das técnicas é que os resultados visuais obtidos com a CLAP são bastante semelhantes aos encontrados na CP, o que vem a determinar a CLAP como técnica de
Funding: No specific financial support was available for this study.

Disclosure of potential conflicts of interest: P.F.M.Tzelikis, None; J.D.dos Santos, None; R.C.Garcez, None; L.Akaishi, None.

Correspondence address: Patrick F. M. Tzelikis. SQN 203 - Bloco G - Apto. 405 - Brasília (DF) 70833-070 - Brazil - E-mail: tzelikis@terra.com.br 
escolha para tratamento de patologias corneanas que não acometem o endotélio(5-6)

No presente trabalho, apresentamos os resultados obtidos após a CLAP pela técnica da "big-bubble" para tratamento de diferentes doenças corneanas que não apresentam comprometimento endotelial.

\section{MÉTODOS}

Este estudo prospectivo, intervencionista, foi desenvolvido no Setor de Córnea e Doenças Externas do Hospital Oftalmológico de Brasília - HOB, após ter sido analisado o protocolo e aprovado pelo Comitê de Ética Médica do HOB. Todos os pacientes incluídos neste estudo foram informados, de forma detalhada, sobre a natureza da investigação, técnica cirúrgica, possíveis riscos e complicações e alternativas de tratamento. Antes da cirurgia e após os devidos esclarecimentos, todos os pacientes assinaram o Termo de Consentimento incluído na pesquisa.

Foram selecionados, consecutivamente, 70 pacientes, portadores de ceratopatia, examinados no ambulatório de Córnea e Doenças Externas do Hospital Oftalmológico de Brasília. Dentre os casos, 59 foram selecionados pelo preenchimento dos critérios de inclusão e constituíram a amostra do estudo. Estes pacientes procuraram o setor de córnea do HOB por demanda espontânea ou foram referenciados por outros setores do mesmo hospital, entre janeiro de 2007 a janeiro de 2010.

Os dados coletados incluem sexo, idade, acuidade visual sem correção (AVSC), acuidade visual com correção (AVCC), equivalente esférico (EE), topografia corneana computadorizada (EyeSys Technologies, Dallas, EUA) e microscopia especular (ME) (NonCon Robo, Konan, Tóquio, Japão) tanto no período pré como pós-operatório, além das complicações intra e pós-operatórias. Neste estudo, as medidas de acuidade visual foram registradas em logMAR.

Os critérios de inclusão eram acuidade visual melhor corrigida pior que 0,30 (logMAR) (20/40) e intolerância ao uso de lentes de contato. Os critérios de exclusão foram: transplante ocular prévio, facectomia prévia, alteração sistêmica que pudesse alterar a cicatrização pós-operatória (diabetes mellitus, doenças autoimunes, doenças do tecido conjuntivo), enfermidade ocular preexistente que pudesse alterar a acuidade visual ou contraindicar a cirurgia (olho seco moderado ou grave, uveíte, glaucoma, doenças retinianas), falta de colaboração para efetuar exames e a cirurgia, e complicações per-operatórias que determinassem a conversão para transplante penetrante.

A avaliação pré-operatória foi realizada em ambos os olhos, dentro do período de 30 dias antes da cirurgia, e incluiu uma revisão da história clínica e oftalmológica dos pacientes e uma série de exames oculares. Cada paciente obteve seus dados coletados no período mínimo de seis meses com alguns pacientes sendo acompanhados por até 24 meses. Os dados foram apresentados para as avaliações realizadas no $6^{\circ} \stackrel{\circ}{1} 12^{\circ}$ e $24^{\circ}$ mês de seguimento pós-operatório.

\section{TÉCNICA CIRÚRGICA}

Todos os pacientes foram operados da mesma maneira e pelo mesmo cirurgião (PT) pela técnica da dissecção por ar (big-bubble). A anestesia em todos os casos foi local, com bloqueio peribulbar utilizando bupivacaína 0,75\% sem vasoconstrictor (Neocaína ${ }^{\circledR}$, Cristália). Por via endovenosa foi utilizado 1,0 mg de midazolam 5,0 mg/ml (Roche, Brasil). Após assepsia e antissepsia da pele com iodo-povidona a 10\% (Cinord Sul, Brasil), equivalente a 1\% de iodo ativo, um campo plástico adesivo era colocado em contato com as pálpebras dos pacientes, de forma a isolar os cílios do campo operatório, e o blefarostato inserido. Uma solução de iodo-povidona a 3\% (Ophthalmos, São Paulo) foi usada com finalidade antisséptica no fundo de saco conjuntival após bloqueio peribulbar.
Na cirurgia, inicialmente era realizada colocação de anel de Flieringa, seguido de trepanação da córnea receptora com diâmetro médio de 8,0 mm (variando entre 7,5 e 8,5, DP: \pm 2,5) em torno de 70\%-80\% da espessura corneana; injeção de ar com agulha $13 x$ 4,5 mm e nos últimos casos injeção de ar através de uma cânula modificada de 27 gauge (Fogla, Storz, Ophthalmics, Bauch \& Lomb); paracentese de 0,8 $\mathrm{mm}$ de tamanho para reduzir a pressão dentro da câmara anterior e realizar injeção de ar para confirmar a separação do estroma da MD; dissecção do estroma profundo com espátula de íris; ceratectomia lamelar até a MD; trepanação da córnea doadora com diâmetro de 0,25 mm superior à córnea receptora, com remoção do endotélio e MD através do uso de azul de tripan; sutura da córnea doada à receptora com 16 pontos separados com mononylon 10.0; injeção subconjuntival de gentamicina $2 \%$ associada à dexametasona 0,002\% (Figura 1).

No período pós-operatório, o paciente foi orientado para utili-

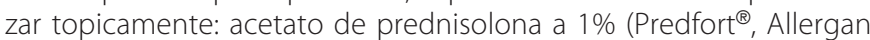
Produtos Farmacêuticos, São Paulo, Brasil) oito vezes ao dia nas primeiras duas semanas com redução gradual até o terceiro mês pós-operatório, gatifloxacina (Zymar ${ }^{\circledR}$, Allergan Produtos Farmacêuticos, São Paulo, Brasil) ou moxifloxacina (Vigamox ${ }^{\circledR}$, Alcon Produtos Farmacêuticos, São Paulo, Brasil) quatro vezes ao dia por 7 dias, e ciclosporina tópica 0,05\% (Restasis ${ }^{\circledR}$, Allergan Produtos Farmacêuticos, São Paulo, Brasil) duas vezes ao dia por quatro meses. Medicação analgésica via oral também foi prescrita em caso de dor A retirada de pontos foi feita a partir do terceiro mês baseada na refração dinâmica e na ceratoscopia computadorizada.

A avaliação estatística dos resultados foi realizada por meio da utilização do programa estatístico SPSS para Windows, versão 12.0 Chicago: SPSS Inc; 2004. Foi realizado o procedimento de análise de variância (ANOVA) para comparação das médias (AVSC, AVCC, EE, astigmatismo topográfico, ME) em diferentes períodos de seguimento. Na presença de diferença entre as médias realizava-se teste de comparações múltiplas de médias (teste de Tukey's post hoc). As diferenças foram consideradas significativas quando $P<0,01$.

\section{RESULTADOS}

Foram avaliados prospectivamente 59 olhos de 55 pacientes submetidos à ceratoplastia lamelar anterior profunda (CLAP), destes 39 (71,0\%) eram homens e 16 (29,0\%) mulheres, com média de idade de $25 \pm 7,9$ anos (variando de 15 a 49 anos). Os diagnósticos pré-operatórios foram: ceratocone em 49 olhos (83,1\%), ectasia corneana pós-cirurgia refrativa em 6 olhos $(10,2 \%)$, distrofia estromal em 2 olhos (3,4\%) e leucoma também em 2 olhos (3,4\%). Dos 59 olhos submetidos à CLAP, 26 olhos (44,1\%) apresentaram acompanhamento de 24 meses, e 30 olhos (50,8\%) 12 meses, sendo observado um acompanhamento pós-operatório médio de 16 meses \pm 7,4 (variando entre 6 e 24 meses).

No exame pré-operatório observava-se uma média de AVSC $(\log M A R)$ de 1,60 (<20/800) (DP: $\pm 0,33)$, variando de 1,00 a 2,00. No período pós-operatório, após 6 meses a média de AVSC era de 0,78 $(20 / 120)(D P: \pm 0,48)(P<0,001)$, após 12 meses a média de AVSC era de $0,86(20 / 150)(D P: \pm 0,39)(P<0,001)$, e ao final de 24 meses a média de AVSC era de 0,82 (20/125) (DP: $\pm 0,33)(P<0,001)$. Em todos os períodos avaliados foi possível observar uma diferença significativa entre o pré e o pós-operatório.

No exame pré-operatório, a média da AVCC era de 1,00 (20/200) (DP: $\pm 0,43$ ), variando de 0,40 a 2,00. No período pós-operatório, após 6 meses a média de AVCC era de 0,35 (20/45) (DP: $\pm 0,20)$ $(P<0.001)$, após 12 meses a média de AVCC era de 0,17 (20/29) (DP: $\pm 0,14)(P<0,001)$, e ao final de 24 meses a média de AVCC era de $0,18(20 / 30)(D P: \pm 0,11)(P<0,001)$. Em todos os períodos avaliados foi possível observar uma diferença significativa entre o pré e o pós-operatório. Ao final de 12 meses 92,0\% dos casos (23 olhos) apresentavam AVCC melhor ou igual a 0,30 logMAR (20/40), 68,0\% 

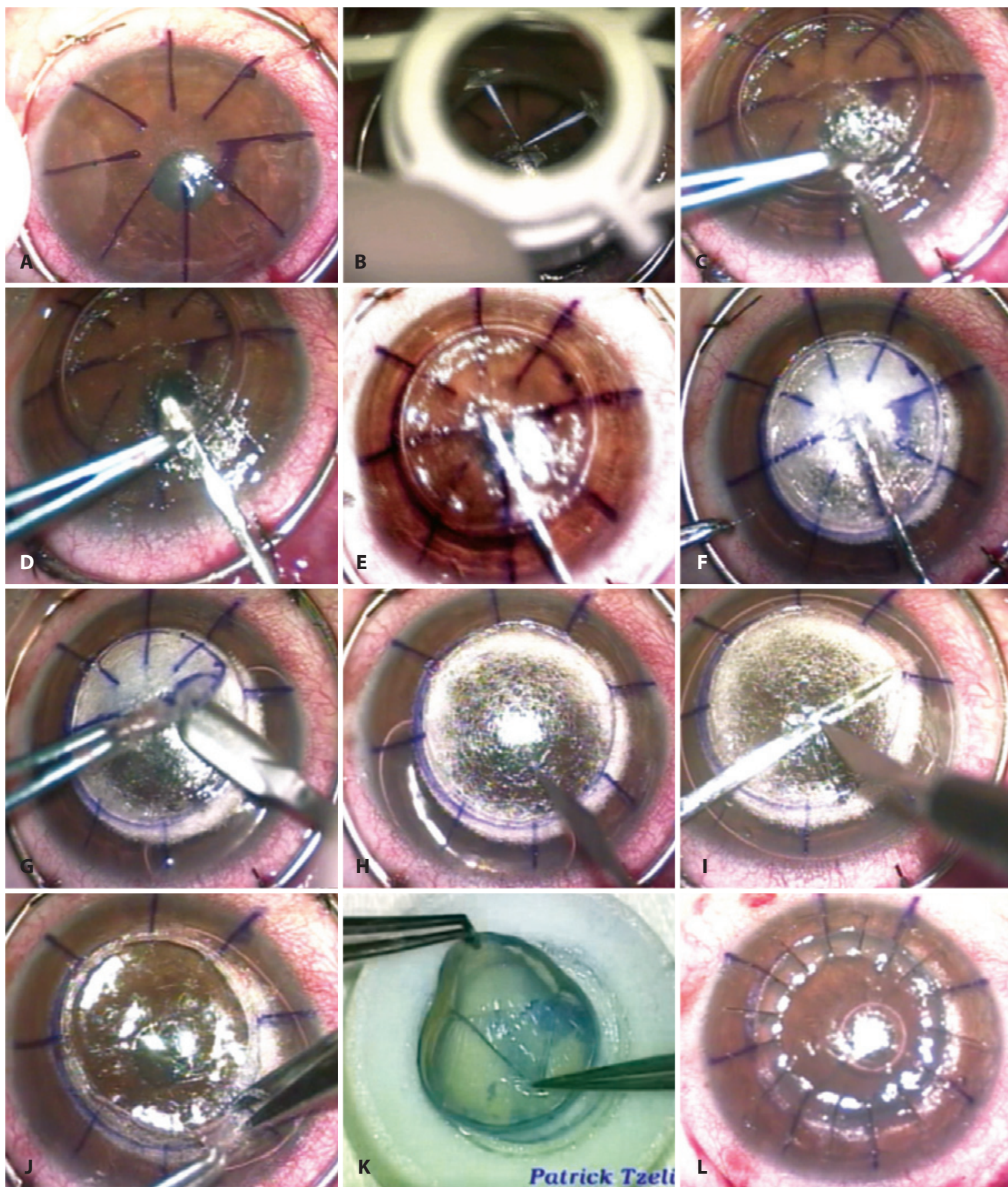

Figura 1. Fotografias intraoperatórias da CLAP. A) Fixação do anel de Flieringa. B) Utilização de trépano a vácuo (Hessburg-Barron) para corte da córnea em profundidade de $70 \%-80 \%$.C) Confecção de uma abertura com agulha $15^{\circ}$ para entrada de espátula. D) Introdução de espátula para dissecar uma abertura até a região central da córnea. E) Introdução de uma cânula 27 gauge modificada (Fogla). F) Injeção de ar com formação de espaço entre o estroma e a membrana de Descemet (big-bubble). G) Dissecção do estroma anterior com lâmina crescente. H) Abertura do espaço localizado entre o plano de clivagem estroma-Descemet. I) Retirada do estroma profundo através de delaminação por sobre a espátula localizada na interface estroma-Descemet. J) Exposição da membrana de Descemet. K) "Peeling" da membrana de Descemet do botão doador. L) Aspecto do transplante ao final da cirurgia.

(17 olhos) AVCC melhor ou igual a 0,18 logMAR (20/30), e 28,0\% (7 olhos) AVCC melhor ou igual a 0,10 logMAR (20/25) (Gráfico 1).

O EE médio pré-operatório na refração dinâmica era de $-8,21 \mathrm{D}$ (DP: $\pm 3,91$ ), variando de $-0,50 \mathrm{D}$ à $-18,00 \mathrm{D}$. No seguimento de 6 meses pós-operatório, a média do EE era de $-1,57$ D (DP: $\pm 3,70$ ) $(P<0,001)$, variando de $+6,00 \mathrm{D}$ à $-7,25 \mathrm{D}$. No seguimento de 12 meses, a média do EE era de $-1,82(D P: \pm 3,62)(P<0,001)$, variando de $+7,25 \mathrm{D}$ à $-7,25 \mathrm{D}$. Ao final de 24 meses de seguimento, a média do EE era de $-2,57 D(D P: \pm 2,85)(P<0,001)$, variando de $+1,00 \mathrm{D}$ à $-7,25$ D. A tabela 1 mostra a topografia corneana nos períodos pré e pós-operatório ao longo do seguimento de 24 meses.

A microscopia especular (ME) foi realizada em todos os pacientes no período pré-operatório, e nos seguimentos de 6, 12 e 24 meses pós-operatório. A contagem endotelial (CE) média pré-ope- 
ratória era de $2.377,98 \mathrm{cél} / \mathrm{s} / \mathrm{mm}^{2}$ (DP: $\pm 263,56$ céls $/ \mathrm{mm}^{2}$ ), variando de 1.545 a 2.985 céls $/ \mathrm{mm}^{2}$. No seguimento de 6 meses a CE média era de 1.985,44 céls $/ \mathrm{mm}^{2}$ (DP: $\pm 375,86$ céls $/ \mathrm{mm}^{2}$ ) ( $\mathrm{n}=57$ olhos), variando de 959 a 2.683 céls $/ \mathrm{mm}^{2}$. No seguimento de 12 meses a CE média era de 1851,32 céls $/ \mathrm{mm}^{2}$ (DP: \pm 397,61 céls $\left./ \mathrm{mm}^{2}\right)$ ( $\mathrm{n}=45$ olhos), variando de 933 a 2.488 céls $/ \mathrm{mm}^{2}$. Ao final de 24 meses a CE média era de 1.874,76 céls $/ \mathrm{mm}^{2}$ (DP: $\pm 428,60$ céls $\left./ \mathrm{mm}^{2}\right) \quad(n=26$ olhos), variando de 976 a 2.397 céls $/ \mathrm{mm}^{2}$. A média de perda endotelial era de 371,52 céls $/ \mathrm{mm}^{2}$ ( \pm 239,21), 453,39 céls $/ \mathrm{mm}^{2}( \pm 251,68)$, e 486,96 céls $/ \mathrm{mm}^{2}$ ( $\pm 309,65$ ) ao final de 6,12 e 24 meses de seguimento, respectivamente. A redução na CE entre o período préoperatório e o pós-operatório encontrou diferença significativa em todos os períodos pós-operatórios estudados $(P<0,001)$. No entanto, não foi encontrada diferença significativa entre os períodos $6 \mathrm{e}$ 12 meses, e, 12 e 24 meses pós-operatórios. A perda endotelial estimada ao final de 6 meses de seguimento foi de $16,5 \%(P<0,001)$, no entanto, entre 6 e 12 meses a perda estimada reduziu para 6,5\%, e entre 12 e 24 meses a perda estimada reduziu para 1,2\%. Não foram excluídos da análise os pacientes que apresentaram microperfurações intraoperatórias (Gráfico 2).

Entre as complicações observadas em nosso estudo, 6 olhos $(10,2 \%)$ apresentaram microperfurações intraoperatória, no entanto, em todos os olhos foi possível completar a ceratoplastia lamelar (Figura 2). No período pós-operatório, um paciente (1,70\%) desen- volveu midríase paralítica (Síndrome de Urrets-Zavalia) sem hipertensão ocular em um dos olhos que apresentou microperfuração intraocular e que havia sido colocada uma bolha de ar na câmara anterior ao final da cirurgia. Apenas um caso $(1,70 \%)$ desenvolveu um episódio de rejeição estromal com aparecimento de discreta opacidade e edema estromal que regrediram rapidamente uma vez iniciado o tratamento com corticóide tópico, evoluindo com transparência corneana. Dois pacientes $(3,4 \%)$ desenvolveram deiscência de sutura após trauma ocular contuso, sendo um após 30 dias de cirurgia e outro após 4 meses. Em nenhum dos casos houve ruptura da membrana de Descemet que permaneceu íntegra mesmo após o trauma sendo necessário realizar apenas a sutura simples da ferida cirúrgica aberta. Considerando esses 10 olhos acima citados, conclui-se que o índice geral de complicações foi de 16,9\%. Os demais pacientes não apresentaram complicações ao longo do seguimento médio de 16 meses.

\section{DISCUSSÃO}

As vantagens de uma cirurgia de transplante de córnea na qual se mantém a membrana de Descemet e o endotélio do receptor em uma ceratoplastia lamelar anterior são geralmente comparadas e balanceadas a uma baixa acuidade visual pós-operatória presente nos casos em que se empregam técnicas lame-

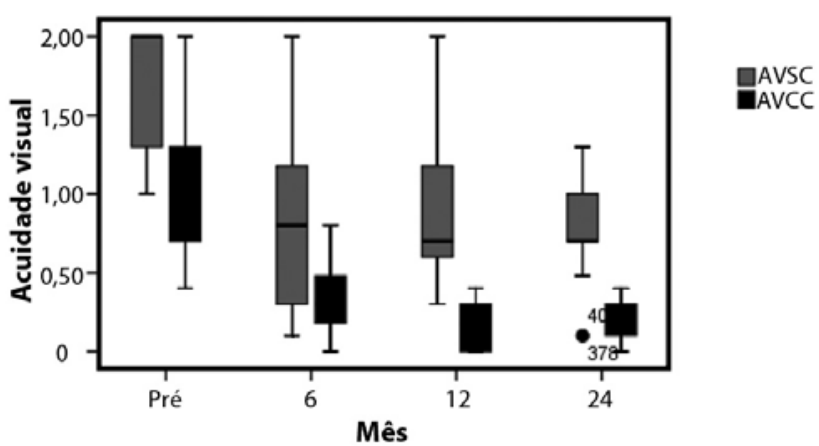

Gráfico 1.Gráficoilustrando a média em logMAR prée pós-operatória da acuidade visual sem correção (AVSC) e acuidade visual com correção (AVCC) durante o seguimento de 24 meses após ceratoplastia lamelar anterior profunda.

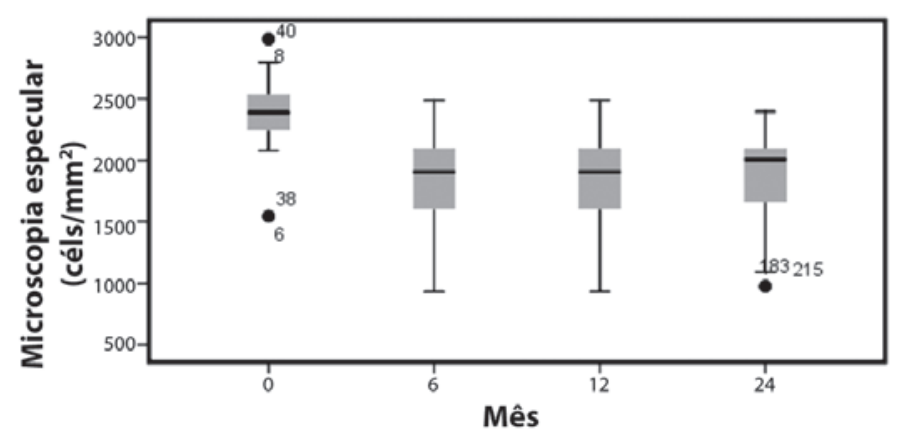

Gráfico 2. Redução da densidade de células endoteliais após ceratoplastia lamelar anterior profunda. Observa-se uma redução acentuada nos primeiros seis meses, seguido de uma diminuição lenta nos meses seguintes.

Tabela 1. Dados médios pré e pós-operatórios (média e desvio padrão)

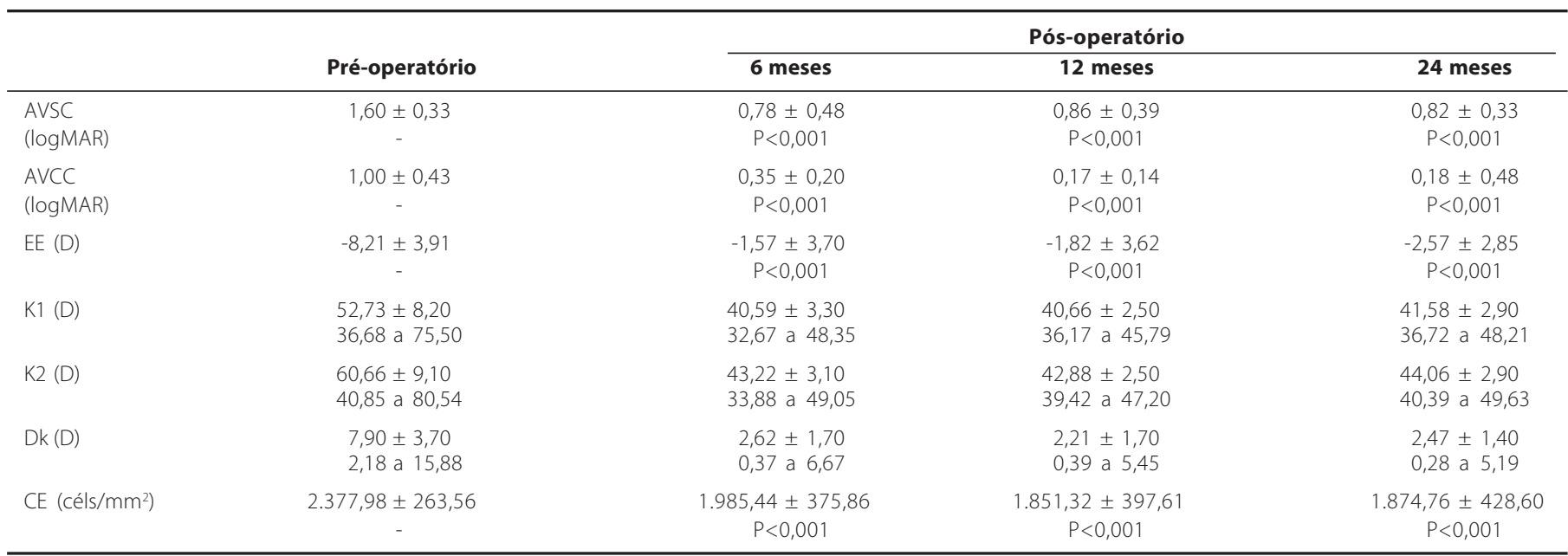

AVSC= acuidade visual sem correção; $A V C C=$ acuidade visual com correção; $E E=$ equivalente esférico; $\mathrm{K} 1=$ ceratometria mais plana; $\mathrm{K} 2=$ ceratometria mais curva; $\mathrm{dK}=$ astigmatismo topográfico; $C E=$ contagem endotelial. Acuidade visual medida em logMAR 

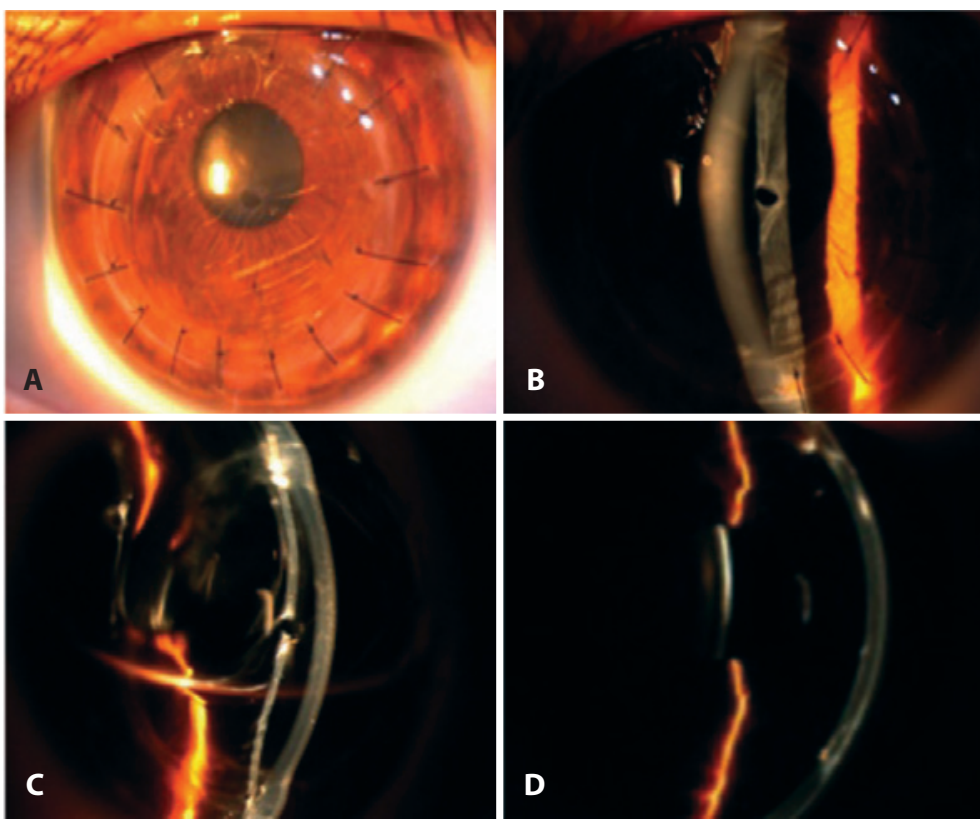

Figura 2. A e B) Presença de microperfuração central no pós-operatório de uma CLAP com formação de uma segunda câmara anterior em um paciente com ceratocone. C) Injeção de ar na câmara anterior realizada na lâmpada de fenda. D) Aspecto do botão corneano ao final de seis meses de acompanhamento com excelente aspecto da interface.

lares convencionais ou de dissecção manual. No entanto, diversos autores vêm apresentando resultados visuais satisfatórios após a ceratoplastia lamelar anterior profunda (CLAP) $)^{(7-10)}$. Recentemente, estudos comparando a CLAP com a ceratoplastia penetrante (CP) mostraram resultados visuais finais semelhantes entre os dois grupos, sendo que a técnica lamelar se mostrou mais segura ${ }^{(11-13)}$. Além da obtenção de uma recuperação visual comparável a CP, a CLAP apresenta uma série de vantagens, principalmente relacionadas à preservação do endotélio do receptor, levando a um menor risco de rejeição endotelial, e consecutivamente, a menor perda por falência endotelial ${ }^{(13)}$

Outros aspectos favoráveis à CLAP são a maior rapidez de cicatrização entre o botão receptor e doador permitindo uma retirada de pontos mais precoce ${ }^{(12)}$, e um menor risco de deiscência de sutura com perda do conteúdo intraocular. No presente trabalho, dois pacientes apresentaram deiscência de sutura pós-trauma, porém em nenhum caso houve abertura da câmara anterior, minimizando consideravelmente as possíveis complicações comparadas a um trauma ocular com ferida a céu-aberto. Apesar de inúmeras vantagens, o procedimento de CLAP apresenta algumas desvantagens teóricas. A CLAP é tecnicamente mais difícil de ser realizada, exigindo maior experiência para sua realização. Ainda é uma técnica em evolução, falta padronização de técnicas, ainda são desconhecidos os seus resultados em longo prazo, e existe um potencial risco de "haze" ou irregularidade na interface doadorreceptor com possível comprometimento no desempenho visual final| ${ }^{(13,14)}$. A presença de tecido cicatricial ou irregular na interface determinando um resultado visual insatisfatório foi um dos principais fatores limitantes da aplicação das técnicas de transplante lamelar no passado ${ }^{(3)}$. Com as novas técnicas de CLAP empregadas atualmente é possível obter uma interface doador-receptor mais regular e com menores índices de opacificação.

O fato de se obter uma interface doador-receptor mais transparente parece estar diretamente relacionado a uma melhor acuidade visual final. No presente estudo, os pacientes obtiveram uma média de acuidade visual corrigida (AVCC) de 20/30 (0,18 logMAR), com $92,0 \%$ dos casos ao final de 12 meses apresentando AVCC melhor ou igual a 0,30 logMAR (20/40). Este resultado visual é comparável a outros estudos em que foram realizadas técnicas de ceratoplastia penetrante ou outras técnicas de CLAP ${ }^{(12-18)}$. No trabalho de Coombes et al..(16), a média de AVCC foi de $20 / 40$ ou melhor em $80 \%$ dos pacientes submetidos à CLAP com dissecção lamelar através da injeção de BSS. Amayem e Anwar ${ }^{(17)}$, em um estudo semelhante envolvendo 24 olhos submetidos à CLAP através da dissecção lamelar com BSS, atingiram uma AVCC de 20/40 ou melhor em $95,8 \%$ dos casos. Fontana et al. ${ }^{(18)}$, utilizando a mesma técnica de dissecção lamelar por nós utilizada, "big-bubble", obtiveram uma AVCC ao final de dois anos de 20/40 ou melhor em $87 \%$ dos pacientes. Watson et al.(13), em um estudo comparando 25 olhos submetidos à CLAP versus 26 olhos submetidos à ceratoplastia penetrante, não encontraram diferença significativa na AVCC, com 87,5\% e 95\% dos olhos atingindo uma AVCC melhor ou igual a 20/40, respectivamente.

Em relação ao equivalente esférico ao final de 24 meses de seguimento o presente estudo encontrou uma média de $-2,57$ dioptrias $(D)$, variando entre $+1,00 \mathrm{D}$ à $-7,25 \mathrm{D}$. Estes resultados são comparáveis a outros estudos em que se observou uma média de EE de -1,65 D (+7,00 D à -10,25 D), $-2,81 \mathrm{D}$ (variando $+0,50$ à $-6,75 \mathrm{D}),-1,81 \mathrm{D}(+3,50 \mathrm{D}$ à $-7,50 \mathrm{D})$, e -2,00 D (+1,75 D à -5,50 D) após CLAP(16-19). Quanto ao astigmatismo topográfico, nosso estudo obteve uma média de -2,47 D (variando -0,28 D à -5,19 D). Resultados semeIhantes são observados na literatura. Anwar e Teichmann (20), em um estudo envolvendo 118 olhos, encontraram uma média de astigmatismo topográfico ao final de 6 meses de seguimento de -3,25 D (variando -1,75 à -8.00 D). Outros estudos relataram astigmatismos de $-2,54 \mathrm{D}(-1,00 \mathrm{D}$ à $-4,00 \mathrm{D}),-3,85 \mathrm{D}(0,00$ à $-8,00 \mathrm{D})$, e $-2,25 \mathrm{D}(-1,50$ à $-3,25)$ após $\mathrm{CLAP}^{(16,17,19)}$. No presente estudo foram utilizadas córneas com diferença de 0,25 mm entre doador e receptor com o objetivo de reduzir a miopia pós-operatória. Fontana et al. ${ }^{(18)}$, utilizaram em seu estudo botão corneano do mesmo tamanho entre doador e receptor obtendo uma média de miopia de -1,81 D. No entanto, relatou a presença de dobras de Descemet em alguns casos em pacientes com valores ceratométricos acentuados no pré-operatório. Na sua grande maioria, as dobras desapareceram uma vez removidas as suturas compressivas.

Em relação às rejeições na CLAP, a sua incidência na literatura vária conforme o estudo apresentado entre 0 a 11,76\% do pacientes ${ }^{(10,15-18)}$. No nosso estudo, a rejeição estromal aconteceu em apenas um caso $(1,70 \%)$ entre 59 olhos estudados. Após um curto período de corticóide tópico o paciente apresentou regressão do quadro, sem nenhuma recorrência.

A frequência de microperfurações relatadas no presente estudo foi de 10,2\% (6/59) dos olhos. Resultados semelhantes também são observados na literatura. Fontana et al. ${ }^{(18)}$, em um estudo envolvendo 81 olhos com ceratocone, relataram a ocorrência de microperfurações em 11 olhos (13\%). Anwar e Teichmannn (20), em um estudo envolvendo 118 olhos, relataram a ocorrência em 9\% dos casos. Shimazaki et al. ${ }^{(11)}$, em um estudo prospectivo comparando CLAP e CP, obtiveram 2 microperfurações (18\%) em 11 olhos submetidos à ceratoplastia lamelar.

No presente estudo, a perda endotelial apresentou uma redução significativa entre os valores pré-operatórios e aqueles obtidos principalmente ao final de 6 meses (16,5\% de perda endotelial), porém assumindo valores próximos ao padrão fisiológico ao final de 24 meses $(1,2 \%)$ de acompanhamento, com uma perda total ao final de 2 anos de seguimento de $24 \%$. Estes resultados são consistentes com outros estudos que apresentaram uma redução média de células endoteliais de aproximadamente $11 \%$ entre 6 e 12 meses, com uma perda endotelial acentuada nos primeiros meses, seguida por uma taxa de 
perda de células fisiológica ${ }^{(13,14)}$. Marchini et al. ${ }^{(9)}$, em um estudo prospectivo envolvendo 46 olhos observaram ao final de 12 meses de seguimento uma perda endotelial média de 17,2\%. A literatura hoje é unânime em afirmar que a CLAP induz uma menor perda de células endoteliais ao longo dos anos, e teoricamente, é livre do risco de rejeição endotelial, o que representa uma grande vantagem uma vez que se reduz o risco de falência do botão transplantado por razões endoteliais ${ }^{(3,11-14)}$. É necessário ser lembrado que a CLAP não é isenta de comprometimento de células endoteliais. Mesmo em casos sem complicação intraoperatória, no presente estudo, ao final de 12 meses, observou-se uma perda média de $20 \%$ nas células endoteliais, o que implica que na presença de baixa contagem endotelial no pré-operatório deve-se evitar a realização da CLAP. Quando comparado ao transplante penetrante, é possível identificar uma grande vantagem do transplante penetrante uma vez que os estudos sugerem que ao final de 2 anos após a cirurgia de CP, pode-se observar uma perda endotelial média de $50 \%$ das células endoteliais ${ }^{(12)}$. No trabalho de Borderie et al. ${ }^{(21)}$, foram observados as diferentes taxas de sobrevivência de um transplante de córnea ao longo dos anos. Ao final do estudo, o que se observou é que a taxa de sobrevivência de um transplante de córnea penetrante ao final de 5 anos era de $74 \%$, ao final de 10 anos de $64 \%$, de 15 anos de 48\%, 20 anos de 27\%, e 30 anos de $2 \%$, o que sugere uma taxa de sobrevida do botão transplantado limitada para duas a três décadas. Já no grupo submetido a transplante lamelar a taxa de sobrevida do botão corneano ao final de 20 anos era de 63,2\% e ao final de 30 anos superior a 10\%. Como conclusão os autores do estudo sugerem a CP como uma boa opção para os pacientes idosos, no entanto, na presença de pacientes jovens, a CP deve ser considerada uma intervenção provisória devendo-se optar quando possível por uma CLAP.

Em conclusão, o presente estudo prospectivo mostrou resultados favoráveis da CLAP realizada pela técnica da "big-bubble" após um seguimento médio de 16 meses, com presença de um número limitado de complicações intraoperatórias. Para pacientes em que o endotélio apresenta-se normal, a ceratoplastia penetrante além de desnecessária acarreta um aumento do risco de rejeição endotelial, que acontece em aproximadamente $20 \%$ dos $\operatorname{casos}^{(2)}$. A maioria dos cirurgiões ainda não opta pela CLAP por ser uma cirurgia tecnicamente mais difícil e longa. Diferentes técnicas como aqui apresentadas, injeção de ar (big-bubble), facilitam consideravelmente o procedimento cirúrgico diminuindo o tempo operatório e tornando a cirurgia mais reproduzível. A ceratoplastia lamelar anterior profunda apresenta-se, portanto, como uma opção terapêutica bastante promissora e provavelmente como primeira escolha em pacientes com ceratopatia e endotélio normal. Estudos prospectivos e comparativos com seguimentos mais longos devem ser reali- zados para melhor avaliação das possíveis vantagens deste procedimento sobre a ceratoplastia penetrante.

\section{REFERÊNCIAS}

1. Brierly SC, Izquierdo L Jr, Mannis MJ. Penetrating keratoplasty for keratoconus. Cornea 2000;19(3):329-32

2. Kirkness CM, Ficker LA, Steele AD, Rice NS. The success of penetrating keratoplasty for keratoconus. Eye (Lond). 1990;4(Pt 5):673-88

3. Shimazaki J. The evolution of lamellar keratoplasty. Curr Opin Ophthalmol. 2000;11(4):217-23.

4. Sugita J, Kondo J. Deep lamellar keratoplasty with complete removal of pathological stroma for vision improvement. Br J Ophthalmol. 1997;81(3):184-8. Comment in Br J Ophthalmol. 1997;81(3):178-9. Br J Ophthalmol. 1998;82(2):205.

5. Shi W, Li S, Gao H, Wang T, Xie L. Modified deep lamellar keratoplasty for the treatment of advanced-stage keratoconus with steep curvature. Ophthalmology. 2010;117(2):226-31.

6. Vajpayee RB, Tyagi J, Sharma N, Kumar N, Jhanji V, Titiyal JS. Deep anterior lamellar keratoplasty by big-bubble technique for treatment corneal stromal opacities. Am J Ophthalmol. 2007 143(6):954-7.

7. Anwar M, Teichmann KD. Big-bubble technique to bare Descemet's membrane in anterio lamellar keratoplasty. J Cataract Refract Surg. 2002;28(3):398-403. Comment in J Cataract Refract Surg. 2002;28(12):2067; author reply 2067-8

8. Trimarchi F, Poppi E, Klersy C, Piacentini C. Deep lamellar keratoplasty. Ophthalmologica 2001:215(6):389-93

9. Marchini G, Mastropasqua L, Pedrotti E, Nubile M, Ciancaglini M, Sbabo A. Deep lamellar keratoplasty by intracorneal dissection: a prospective clinical and confocal microscopic study. Ophthalmology. 2006;113(8):1289-300.

10. Macedo JP, Forseto AS, Allemann N, Sousa LB. Avaliação da ceratoplastia lamelar anterior profunda em pacientes com ceratocone. Arq Bras Oftalmol. 2009:72(4):486-92.

11. Shimazaki J, Shimmura S, Ishioka M, Tsubota K. Randomized clinical trial of deep lamellar keratoplasty vs penetrating keratoplasty. Am J Ophthalmol. 2002;134(2):159-65.

12. Panda A, Bageshwar LM, Ray M, Singh JP, Kumar A. Deep lamellar keratoplasty versus penetrating keratoplasty for corneal lesions. Cornea. 1999;18(2):172-5.

13. Watson SL, Ramsay A, Dart JK, Bunce C, Craig E. Comparison of deep lamellar keratoplasty and penetrating keratoplasty in patients with keratoconus. Ophthalmology. 2004;111(9):1676-82.

14. van Dooren BT, Mulder PG, Nieuwendaal CP, Beekhuis WH, Melles GR. Endothelial cel density after deep anterior lamellar keratoplasty (Melles technique). Am J Ophthalmol. 2004;137(3):397-400

15. Lim L, Pesudovs K, Coster DJ. Penetrating keratoplasty for keratoconus: visual outcome and success. Ophthalmology. 2000:107(6):1125-31.

16. Coombes AG, Kirwan JF, Rostron CK. Deep lamellar keratoplasty with lyophilisied tissue in the management of keratoconus. Br J Ophthalmol. 2001;85(7):788-91.

17. Amayem AF, Anwar M. Fluid lamellar keratoplasty in keratoconus. Ophthalmology. 2000; 107(1):76-9; discussion 80

18. Fontana L, Parente G, Tassinari G. Clinical outcomes after deep anterior lamellar keratoplasty using the big-bubble technique in patients with keratoconus. Am J Ophthalmol. 2007;143(1):117-24

19. Krumeich JH, Daniel J, Knülle A. Live-epikeratophakia for keratoconus. J Cataract Refract Surg. 1998;24(4):456-63.

20. Anwar M, Teichmann KD. Deep lamellar keratoplasty: surgical techniques for anterio lamellar keratoplasty with and without baring of Descemet's membrane. Cornea. 2002 21(4):374-83.

21. Borderie VM, Boëlle PY, Touzeau O, Allouch C, Boutboul S, Laroche L. Predicted long term outcome of corneal transplantation. Ophthalmology. 2009;116(12):2354-60. 